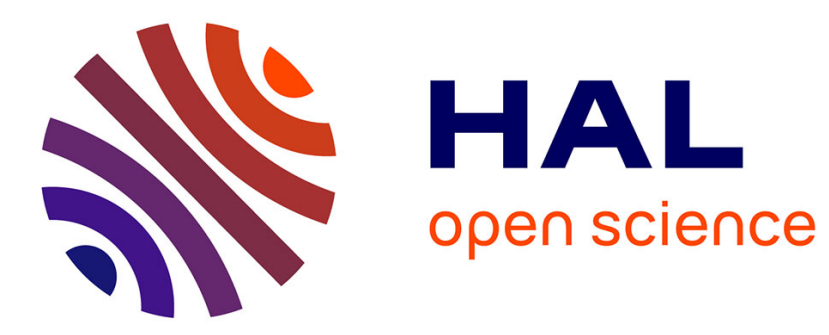

\title{
Model predictive power control based on virtual flux for grid connected three-level neutral-point clamped inverter
}

Binh Quang Van Ngo, Pedro Rodriguez-Ayerbe, Sorin Olaru, Silviu-Iulian

Niculescu

\section{To cite this version:}

Binh Quang Van Ngo, Pedro Rodriguez-Ayerbe, Sorin Olaru, Silviu-Iulian Niculescu. Model predictive power control based on virtual flux for grid connected three-level neutral-point clamped inverter. 18th European Conference on Power Electronics and Applications, Sep 2016, Karlsruhe, Germany. 10.1109/EPE.2016.7695299 . hal-01813508

\author{
HAL Id: hal-01813508 \\ https://hal.science/hal-01813508
}

Submitted on 11 Apr 2020

HAL is a multi-disciplinary open access archive for the deposit and dissemination of scientific research documents, whether they are published or not. The documents may come from teaching and research institutions in France or abroad, or from public or private research centers.
L'archive ouverte pluridisciplinaire HAL, est destinée au dépôt et à la diffusion de documents scientifiques de niveau recherche, publiés ou non, émanant des établissements d'enseignement et de recherche français ou étrangers, des laboratoires publics ou privés. 


\title{
Model Predictive Power Control based on Virtual Flux for Grid connected Three-level Neutral-Point Clamped Inverter
}

\author{
Binh Quang Van Ngo*, Pedro Rodriguez-Ayerbe*, Sorin Olaru* and Silviu-Iulian Niculescu** \\ * L2S, Université Paris-Saclay, CentraleSupélec \\ Email: Binhvanquang.Ngo@supelec.fr; Pedro.Rodriguez@centralesupelec.fr \\ Sorin.Olaru@centralesupelec.fr \\ ** L2S, CNRS-CentraleSupélec (email: Silviu.Niculescu@12s.centralesupelec.fr) \\ 91192 Gif-sur-Yvette, France
}

\section{Keywords}

$\ll$ Multilevel converters $\gg, \ll$ Finite Control Set Model Predictive Control $\gg, \ll$ Direct power control $\gg$, $\ll$ Converter control $\gg, \ll$ Control methods for electrical systems $\gg$.

\begin{abstract}
The paper presents a detailed description of the prediction model for Predictive Power Control based on Virtual Flux (MPPC-VF) scheme for control grid connected three-level neutral-point clamped inverter (3L-NPC). The controller uses a model to calculate predictions of the future values of the virtual flux, grid currents and DC-link capacitor voltages for all possible voltage vectors. The active and reactive power can be estimated based on the virtual flux and the current. The cost function is defined to minimize the error between the active, reactive power and their references, balance the DC-link capacitor voltage and reduce the switching frequency. The optimal switching state that minimizes the cost function is selected and applied to the inverter. Simulation results under different conditions are presented and compared with conventional Direct Power Control and Space Vector Modulation (DPC-SVM). The obtained results show the better performances of the proposed control method.
\end{abstract}

\section{Introduction}

The multilevel converters represent an attractive solution for high power applications due to its ability to meet the increasing capacity requirements and power quality associated with reduced harmonic distortion and have been shown in the recent years to offer high performance compared with the two-level converters. In particular, the three-level neutral point clamped (3L-NPC) inverter structure is considered to be a good solution due to the following advantages: capability to reduce the output voltage and current harmonic content, common mode voltage and increasing the capacity of the converter thanks to a decreased voltage applied to each power semiconductor [1], [2].

Grid connected power inverters plays an important role in industrial applications such as new energy systems, high voltage direct current transmission, flexible AC transmission systems (FACTS), especially with the development of high power generators using wind power. Most of the existing control method use the voltage-oriented control (VOC) which guarantees high dynamics and static performance via internal current control loops [2]. However, it has a low dynamic performance and its performances depend on the quality of the current control loop, which is strongly influenced by unbalanced grid voltages. Better performances are obtained with the look up table direct power control (LUT-DPC). In this technique, the optimal switching status is selected by a switching table based on the instantaneous error between the reference values and estimated values of the active and reactive power and voltage or virtual flux position vector [3], [4]. The drawback of LUT-DPC is that the switching frequency would not remain constant. However, this problem can be solved by using pulse width modulation (PWM), space vector modulation 


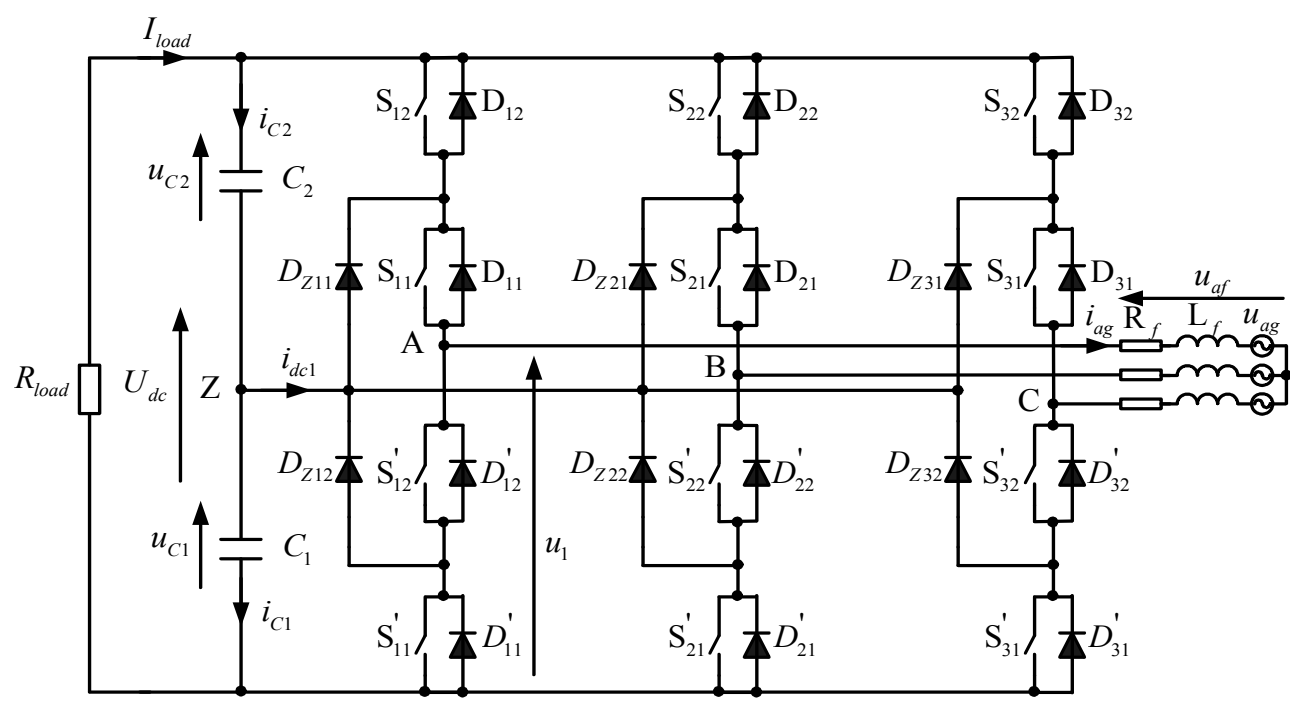

Fig. 1: The configuration of the grid connected three-level neutral point clamped inverter

(SVM) [5] or predictive control strategy, [6]. Model predictive control (MPC) has been successfully used in industrial applications due to its advantages, such as easy inclusion of non-linearities in the model, constraint and delay compensation [1], [7], [8].

The present paper presents the model MPPC-VF to control the active and reactive power for grid connected 3L-NPC while maintaining the balance between the DC link capacitor voltage and reducing the switching frequency. These objectives are accomplished through the cost function in a predictive control strategy. No current loop is considered and the inverter switches are directly obtained from cost function minimization. This control allows to improve the quality of the power regulation and to minimize the switching losses. A control horizon of two is used for the prediction, where only combination of inputs having a difference of one switch in the inverter is considered.

This paper is organized as follow: section 2 presents the mathematical prediction model for direct power control for grid connected three-level inverter. Section 3 details the proposed control method. In section 4, simulation results are represented and analyzed and finally section 5 draws the conclusion.

\section{Model predictive power control based on virtual flux for grid connected 3L- NPC inverter}

\section{Topology}

A simplified diagram of the grid connected three-level neutral point clamped inverter is presented in Fig. 1. The operating status of 3L-NPC switches can be represented by three switching states [P], [O] and [N]. The switching state [P] or [1] signifies both $S_{11}$ and $S_{12}$ switches in branch A are states "ON" and the inverter terminal voltage $U_{A Z}$ has the value $+U_{d c} / 2$, while [N] or [-1] indicates two switches $S_{11}$ and $S_{12}$ are conditions "OFF", leading to $U_{A Z}=-U_{d c} / 2$. The switching state [O] or [0] means that the two internal switch $S_{11}$ and $S_{12}^{\prime}$ are states "ON"and $U_{A Z}$ is clamped to zero through the clamping diodes. Taking into account the three phases of the inverter, there are in total 27 possible combinations of switching states corresponding to 19 voltage vectors.

\section{Mathematical model}

The neutral-point current $i_{d c 1}$ can be calculated from three-phase grid currents and the switching states as follows [9]:

$$
i_{d c 1}=i_{c 2}-i_{c 1}=\left(1-\left|S_{a}\right|\right) i_{a g}+\left(1-\left|S_{b}\right|\right) i_{b g}+\left(1-\left|S_{c}\right|\right) i_{c g}
$$




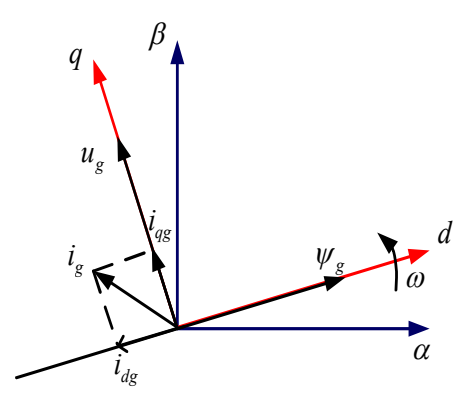

Fig. 2: Reference coordinates and vectors

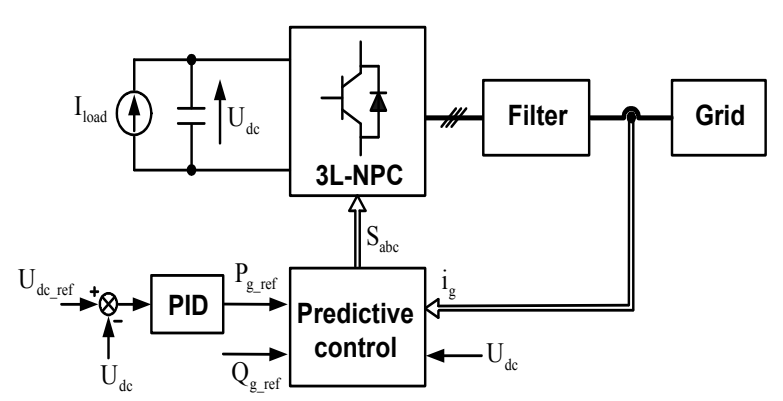

Fig. 3: Block diagram of MPPC-VF scheme

where $S_{x}$ represents the state of a leg and has three possible values: $[-1,0,1]$.

Assuming that the DC bus voltage $U_{d c}$ is constant and $C_{1}=C_{2}=C$, the neutral-point voltage can be expressed as follows:

$$
\frac{d u_{z}}{d t}=-\frac{1}{2 C}\left(i_{c 2}-i_{c 1}\right)=-\frac{1}{2 C}\left(\left(1-\left|S_{a}\right|\right) i_{a g}+\left(1-\left|S_{b}\right|\right) i_{b g}+\left(1-\left|S_{c}\right|\right) i_{c g}\right)
$$

By using the Clarke transformation, the dynamic of neutral-point voltage $u_{z}$ can be written as follows:

$$
\frac{d u_{z}}{d t}=\frac{1}{4 C}\left(\left(2\left|S_{a}\right|-\left|S_{b}\right|-\left|S_{c}\right|\right) i_{g \alpha}+\sqrt{3}\left(\left|S_{b}\right|-\left|S_{c}\right|\right) i_{g \beta}\right)
$$

Furthermore, the system configured by the grid side inverter, filter and grid voltage can be represented as follows:

$$
u_{i n v}=u_{g}+R_{f} i_{g}+L_{f} \frac{d i_{g}}{d t}
$$

where $u_{g}, i_{g}$ : are the grid voltage and current and $R_{f}, L_{f}:$ are the resistance and inductance filter

The inverter output voltage $u_{i n v}$ can be estimated by the measured DC link voltage and exploiting the knowledge of the current switching state. After the $\alpha \beta$ transformation this can be expressed as:

$$
u_{i n v}=u_{i n v \alpha}+j u_{i n v \beta}=\frac{U_{d c}}{3}\left(S_{a}-\frac{S_{b}}{2}-\frac{S_{c}}{2}+j\left(\frac{\sqrt{3}}{2} S_{b}-\frac{\sqrt{3}}{2} S_{c}\right)\right)
$$

On the other hand, from the Fig. 2, we can calculate the grid voltage from the virtual flux of the grid $\psi_{g}$ as:

$$
\begin{aligned}
& u_{g \alpha}=\frac{d \psi_{g \alpha}}{d t}=-\left|\psi_{g}\right| \omega \sin \omega t=-\omega \psi_{g \beta} \\
& u_{g \beta}=\frac{d \Psi_{g \beta}}{d t}=\left|\psi_{g}\right| \omega \cos \omega t=\omega \psi_{g \alpha}
\end{aligned}
$$

Based on equation (4) and (6) we can express the grid current as follows:

$$
\begin{aligned}
& \frac{d i_{g \alpha}}{d t}=\frac{1}{L_{f}}\left(u_{i n v \alpha}+\omega \Psi_{g \beta}-R_{f} i_{g \alpha}\right) \\
& \frac{d i_{g \beta}}{d t}=\frac{1}{L_{f}}\left(u_{i n v \beta}-\omega \psi_{g \alpha}-R_{f} i_{g \beta}\right)
\end{aligned}
$$

Consequently, we have the continuous-time dynamics of the system based on the equation (3), (5), (6) 
and (7):

$$
\begin{aligned}
\frac{d i_{g \alpha}}{d t} & =\frac{1}{L_{f}}\left(\frac{U_{d c}}{6}\left(2 S_{a}-S_{b}-S_{c}\right)+\omega \psi_{g \beta}-R_{f} i_{g \alpha}\right) \\
\frac{d i_{g \beta}}{d t} & =\frac{1}{L_{f}}\left(\frac{U_{d c}}{2 \sqrt{3}}\left(S_{b}-S_{c}\right)-\omega \psi_{g \alpha}-R_{f} i_{g \beta}\right) \\
\frac{d \psi_{g \alpha}}{d t} & =-\omega \psi_{g \beta} \\
\frac{d \psi_{g \beta}}{d t} & =\omega \psi_{g \alpha} \\
\frac{d u_{z}}{d t} & \left.=\frac{1}{4 C}\left(\left(2\left|S_{a}\right|-\left|S_{b}\right|-\left|S_{c}\right|\right) i_{g \alpha}+\sqrt{3}\left(\left|S_{b}\right|\right)-\left|S_{c}\right|\right) i_{g \beta}\right)
\end{aligned}
$$

The instantaneous active and reactive powers can be calculated as follows [3]:

$$
\begin{gathered}
P_{g}=\frac{3}{2}\left(u_{g \alpha} i_{g \alpha}+u_{g \beta} i_{g \beta}\right)=\frac{3}{2} \omega\left(\psi_{g \alpha} i_{g \beta}-\psi_{g \beta} i_{g \alpha}\right) \\
Q_{g}=\frac{3}{2}\left(u_{g \beta} i_{g \alpha}-u_{g \alpha} i_{g \beta}\right)=\frac{3}{2} \omega\left(\psi_{g \alpha} i_{g \alpha}+\psi_{g \beta} i_{g \beta}\right)
\end{gathered}
$$

where $\omega$ is the angular frequency of the grid

\section{The application of MPPC-VF for grid connected to 3L-NPC inverter}

The aim of the predictive direct power control scheme is to minimize the error between the predicted active and reactive powers and their reference values, to maintain voltage balance of the capacitor and to reduce the switching frequency (Fig. 3). In order to achieve these objectives, the cost function for 3L-NPC will use the following ingredients suggested in [1], [7], [8]:

$$
g=\left|P_{g}^{*}-P_{g}^{p}\right|+\left|Q_{g}^{*}-Q_{g}^{p}\right|+\lambda_{d c}\left|u_{z}^{p}\right|+\lambda_{n} n_{c}
$$

Where $P_{g}^{p}$ and $Q_{g}^{p}$ are the predicted active and reactive powers; $P_{g}^{*}$ and $Q_{g}^{*}$ are the reference values for active and reactive powers.

In the cost function (10) $n_{c}$ penalises the number of switching change when the switching state $\mathrm{S}(\mathrm{k})$ is applied compared with previous state $\mathrm{S}(\mathrm{k}-1)$. It can be expressed as follows:

$$
n_{c}=\left|S_{a}(k)-S_{a}(k-1)\right|+\left|S_{b}(k)-S_{b}(k-1)\right|+\left|S_{c}(k)-S_{c}(k-1)\right|
$$

And $\lambda_{d c}, \lambda_{n}$ are the weighting factor of the capacitor voltage balancing and the reduction of commutation.

In the real time implementation, because of calculation time of the control law, there will be a sample time delay in the actuation [7], [8]. A simple solution to compensate the computational delay is at time instant $\mathrm{k}$ to compute the cost function corresponding to time instant $\mathrm{k}+1$ using an estimation of the state at time $\mathrm{k}+1$ and then the optimal switching state is applied at time $\mathrm{k}+1$. As previously mentioned, there are 27 voltage vectors which have to be evaluated within one step prediction. When two steps are considered for prediction, a discrete set of $27^{2}$ possible trajectories of the voltage vector have to be considered. Consequently, their evaluation leads to large number of cost computations and make difficult to implement the algorithm in practice. In order to reduce the numbers of real time evaluations only combinations of inputs having one switching variation are considered, as illustrated in Fig. 4. For

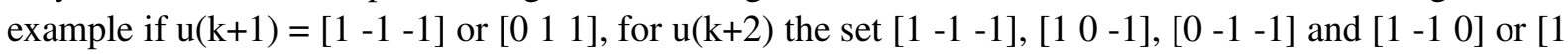

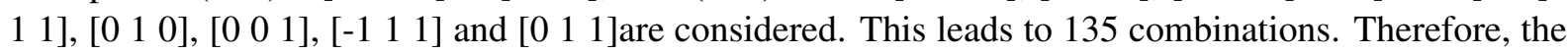
computations required are limited with respect to the total of $27^{2}=729$ trajectories. 


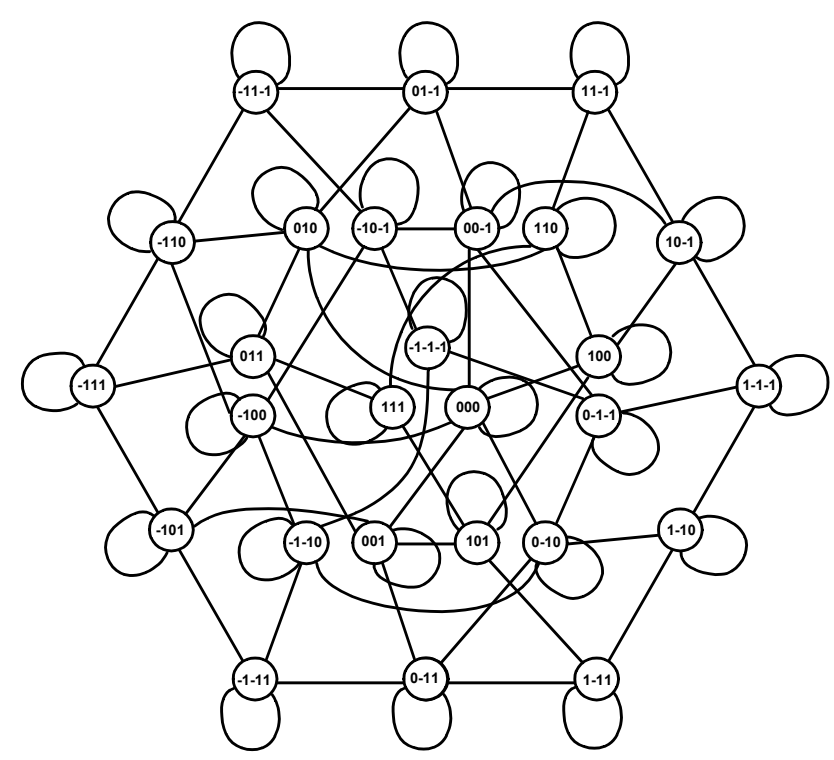

Fig. 4: The switching transitions of 3L-NPC inverter

Where the resistance is neglected, the virtual grid flux $\psi_{g}$ can be estimated by the virtual flux of the inverter $\psi_{i n v}$ as:

$$
\psi_{g}=\psi_{i n v}-L_{f} i_{g}
$$

According to equation (8), the grid currents are represented in discrete-time by using the first-order forward Euler approximation as follows:

$$
\begin{aligned}
& i_{g \alpha}^{p}(k+1)=\left(1-\frac{R_{f} T_{s}}{L_{f}}\right) i_{g \alpha}(k)+\frac{T_{s}}{L_{f}} \omega \psi_{g \beta}(k)+\frac{T_{s}}{6 L_{f}} U_{d c}\left(2 S_{a}(k)-S_{b}(k)-S_{c}(k)\right) \\
& i_{g \beta}^{p}(k+1)=\left(1-\frac{R_{f} T_{s}}{L_{f}}\right) i_{g \beta}(k)-\frac{T_{s}}{L_{f}} \omega \Psi_{g \alpha}(k)+\frac{T_{s}}{2 \sqrt{3} L_{f}} U_{d c}\left(S_{b}(k)-S_{c}(k)\right)
\end{aligned}
$$

Thus, the discrete-time forms for grid currents are expressed at instant $\mathrm{k}+2$ as follows:

$$
\begin{aligned}
& i_{g \alpha}^{p}(k+2)=\left(1-\frac{R_{f} T_{s}}{L_{f}}\right) i_{g \alpha}^{p}(k+1)+\frac{T_{s}}{L_{f}} \omega \psi_{g \beta}^{p}(k+1)+\frac{T_{s}}{6 L_{f}} U_{d c}\left(2 S_{a}(k+1)-S_{b}(k+1)-S_{c}(k+1)\right) \\
& i_{g \beta}^{p}(k+2)=\left(1-\frac{R_{f} T_{s}}{L_{f}}\right) i_{g \beta}^{p}(k+1)-\frac{T_{s}}{L_{f}} \omega \psi_{g \alpha}^{p}(k+1)+\frac{T_{s}}{2 \sqrt{3} L_{f}} U_{d c}\left(S_{b}(k+1)-S_{c}(k+1)\right)
\end{aligned}
$$

where the grid virtual flux $\psi_{g \alpha}(k), \psi_{g \beta}(k)$ are estimated from the equations (5) and (12).

In the same way, the grid virtual fluxes are expressed based on the equation (8) and (12) as:

$$
\begin{aligned}
& \psi_{g \alpha}^{p}(k+1)=\psi_{i n v \alpha}^{p}(k+1)-L_{f} i_{g \alpha}^{p}(k+1) \\
& \psi_{g \beta}^{p}(k+1)=\psi_{i n \nu \beta}^{p}(k+1)-L_{f} i_{g \beta}^{p}(k+1) \\
& \psi_{g \alpha}^{p}(k+2)=\psi_{g \alpha}^{p}(k+1)-T_{s} \omega \psi_{g \beta}^{p}(k+1) \\
& \psi_{g \beta}^{p}(k+2)=\psi_{g \beta}^{p}(k+1)+T_{s} \omega \psi_{g \alpha}^{p}(k+1)
\end{aligned}
$$

The evolution of neutral-point voltage for two-step prediction is obtained by using equation (8). Then its 
expression is given by:

$$
\begin{aligned}
u_{z}^{p}(k+1) & =u_{z}(k)+\frac{\sqrt{3} T_{s}}{4 C}\left(\left|S_{b}(k)\right|-\left|S_{c}(k)\right|\right) i_{g \beta}(k)+\frac{T_{s}}{4 C}\left(2\left|S_{a}(k)\right|-\left|S_{b}(k)\right|-\left|S_{c}(k)\right|\right) i_{g \alpha}(k) \\
u_{z}^{p}(k+2) & =u_{z}^{p}(k+1)+\frac{\sqrt{3} T_{s}}{4 C}\left(\left|S_{b}(k+1)\right|-\left|S_{c}(k+1)\right|\right) i_{g \beta}^{p}(k+1) \\
& +\frac{T_{s}}{4 C}\left(2\left|S_{a}(k+1)\right|-\left|S_{b}(k+1)\right|-\left|S_{c}(k+1)\right|\right) i_{g \alpha}^{p}(k+1)
\end{aligned}
$$

As a result, the cost function of MPPC-VF for the grid connected 3L-NPC inverter with two-step prediction can be expressed as follows:

$$
g=\left|P_{g}^{*}(k+2)-P_{g}^{p}(k+2)\right|+\left|Q_{g}^{*}(k+2)-Q_{g}^{p}(k+2)\right|+\lambda_{d c}\left|u_{z}^{p}(k+2)\right|+\lambda_{n} n_{c}
$$

The future powers $P_{g}^{*}(k+2)$ and $Q_{g}^{*}(k+2)$ are estimated by extrapolation using Lagrange method based on the present and passed values. This process can be expressed as follows [1]:

$$
\begin{aligned}
& P_{g}^{*}(k+2)=6 P_{g}^{*}(k)-8 P_{g}^{*}(k-1)+3 P_{g}^{*}(k-2) \\
& Q_{g}^{*}(k+2)=6 Q_{g}^{*}(k)-8 Q_{g}^{*}(k-1)+3 Q_{g}^{*}(k-2)
\end{aligned}
$$

Finally, the objective of proposed predictive control can be obtained by evaluation of the cost function for all trajectories (see algorithm 1).

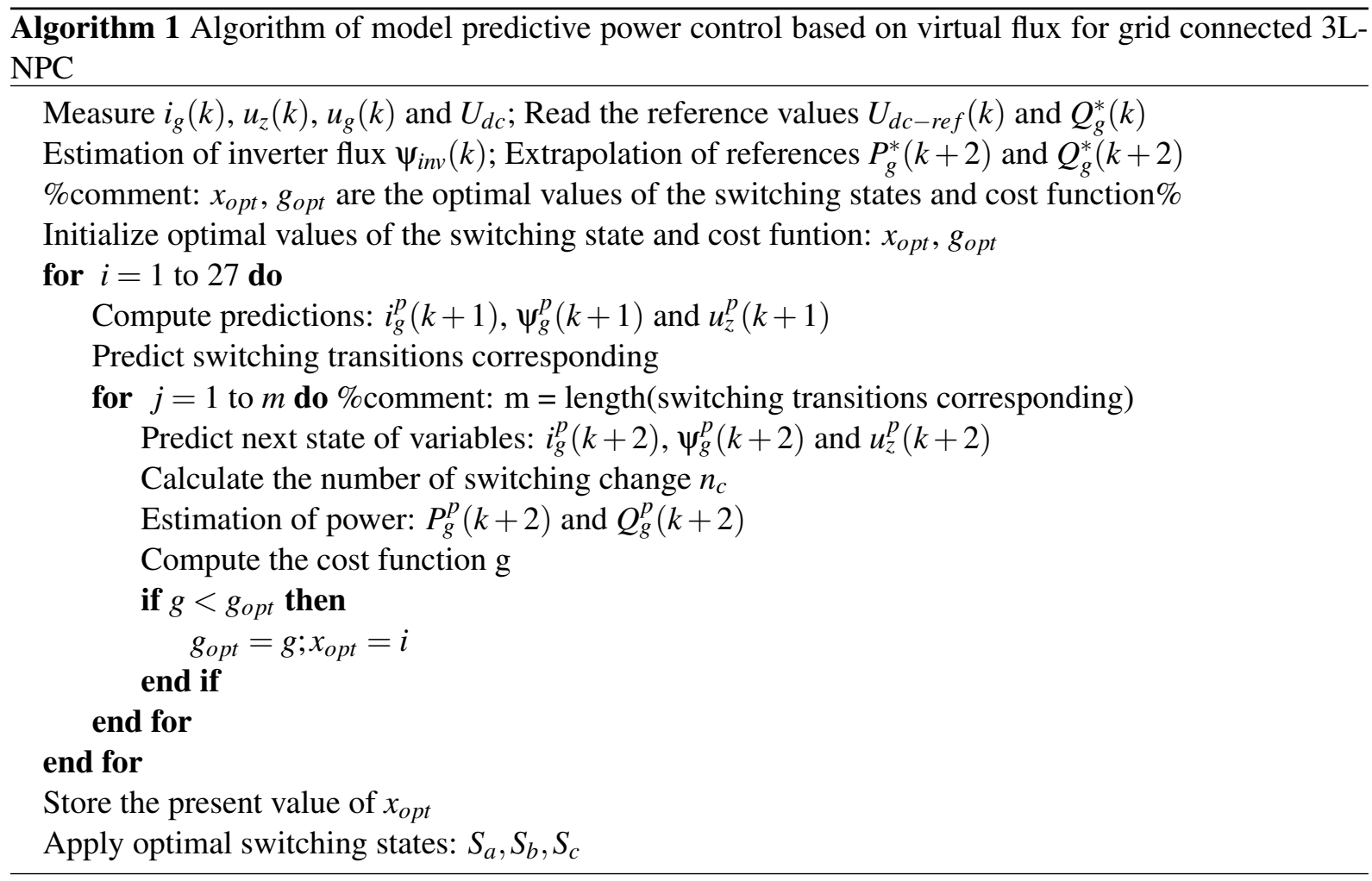

\section{Simulation results}

To analysis the operation of the MPPC-VF system under different conditions, the whole control scheme has been simulated using Matlab software with the parameters as indicated in Table I.

In order to evaluate the steady state performance, one can use the mean absolute percentage error (MAPE) 


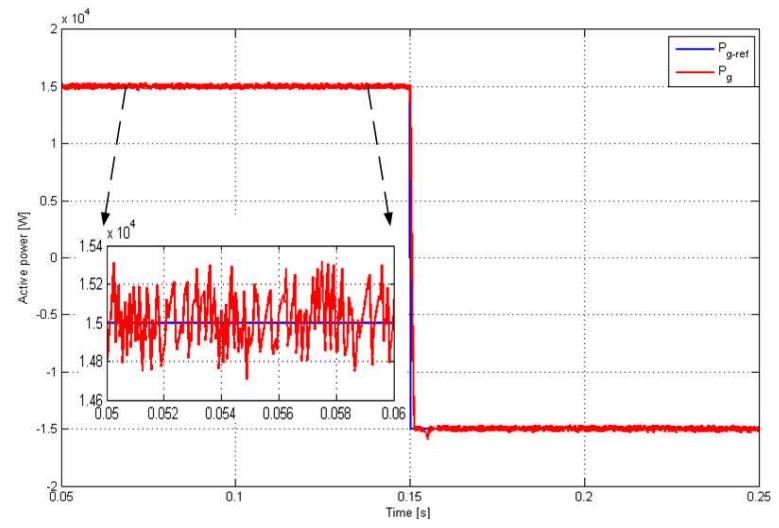

(a) Active power

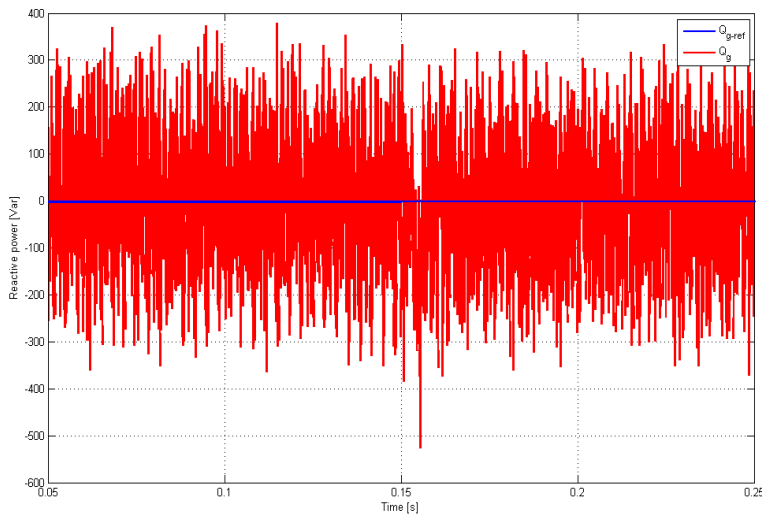

(b) Reactive power

Fig. 5: The transient power responses for a step in the active power reference from 15 to $-15 \mathrm{~kW}$

which can be express as follows:

$$
M A P E=\frac{1}{n} \sum_{i=1}^{n}\left|\frac{y_{i}^{*}-y_{i}}{y_{i}^{*}}\right|
$$

where $y_{i}^{*}$ is the reference vector and $y_{i}$ is the vector measured.

On other hand, in an attempt to estimate the average switching frequency per semiconductor $\left(\overline{f_{s w}}\right)$ of MPPC-VF, the following expression proposed in [1] can serve as appropriate indicator:

$$
\overline{f_{s w}}=\sum_{x=a, b, c} \frac{f_{s w_{1 x}}+f_{s w_{2 x}}}{6}
$$

where $f_{s w_{1 x}}, f_{s w_{2 x}}$ are the switching frequency of each upper switch and are calculated by measuring the number of switching changes in the gating signals for 15 fundamental cycles.

Table I: Electrical and control parameters for simulation

\begin{tabular}{|c|c|l|}
\hline Parameter & Value & Description \\
\hline$U_{d c}$ & $600[\mathrm{~V}]$ & DC-link voltage \\
$\mathrm{C}$ & $940[\mu \mathrm{F}]$ & DC-link capacitor \\
$R_{f}$ & $80[\mathrm{~m} \Omega]$ & Grid-side filter resistance \\
$L_{f}$ & $10[\mathrm{mH}]$ & Grid-side filter inductance \\
$f_{s}$ & $20[\mathrm{kHz}]$ & Sampling frequency for MPPC-VF \\
$f_{s v m}$ & $5[\mathrm{kHz}]$ & Sampling frequency for DPC-SVM \\
$\mathrm{f}$ & $50[\mathrm{~Hz}]$ & Frequency of the grid \\
$\mathrm{U}$ & $220[\mathrm{~V}]$ & Rated phase grid voltage \\
$P_{d m}$ & $15[\mathrm{~kW}]$ & Rated active power \\
$I_{d m}$ & $32[\mathrm{~A}]$ & Rated current \\
\hline
\end{tabular}

The performance of the proposed method for power control was tested by applying a step in the active power reference $P_{g}^{*}$ without DC bus voltage control. The step change in $P_{g}^{*}$ from 15 to $-15 \mathrm{~kW}$ is applied at $\mathrm{t}=0.15 \mathrm{~s}$, with a unity power factor reactive power set point set to zero $Q_{g}^{*}=0$ (Fig. 5). The active power tracks the assigned reference with very good performance in what it may concern during the transient and steady-state conditions. The phase shift between the voltage and current is also shown for this change in the power factor (Fig.6).

With the purpose of verify the dynamic performances, we perform a comparison between MPPC-VF and 


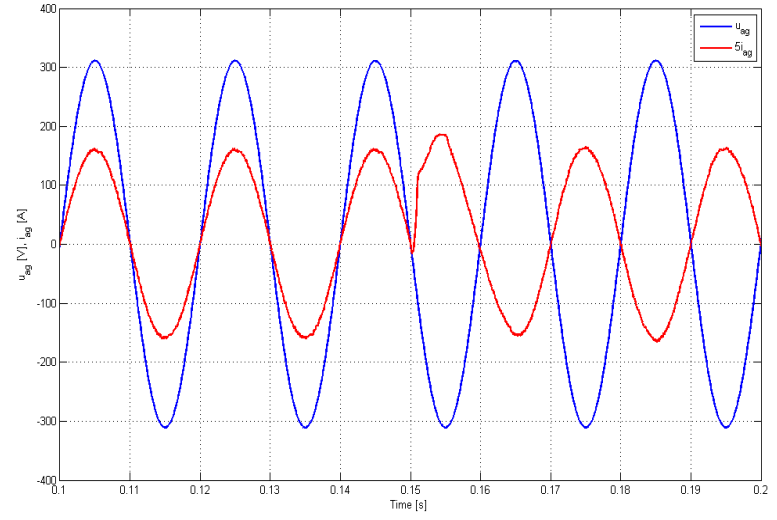

Fig. 6: The responses of voltage and current

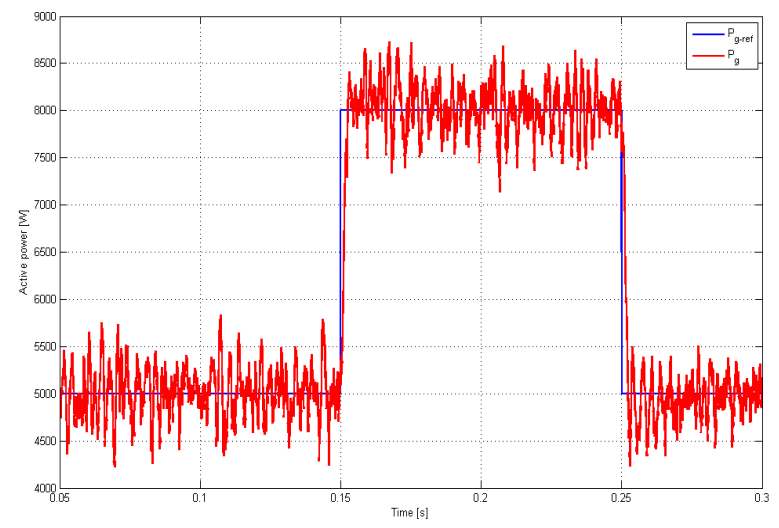

(a) DPC-SVM

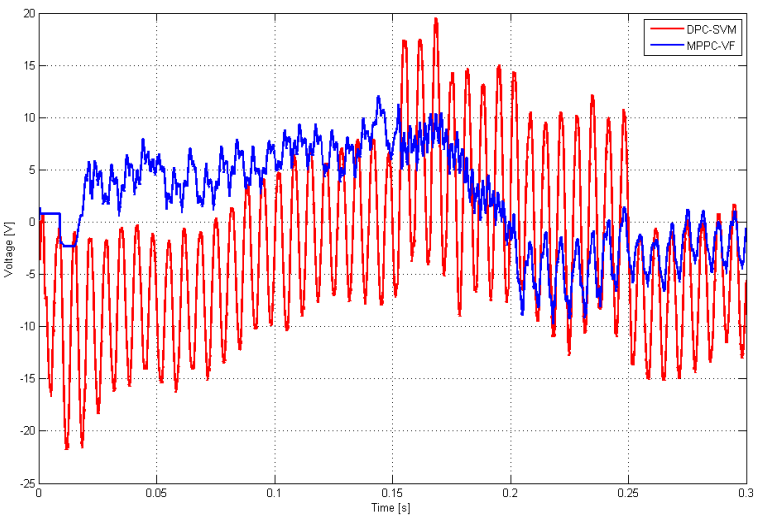

Fig. 7: Performance of the $u_{z}$

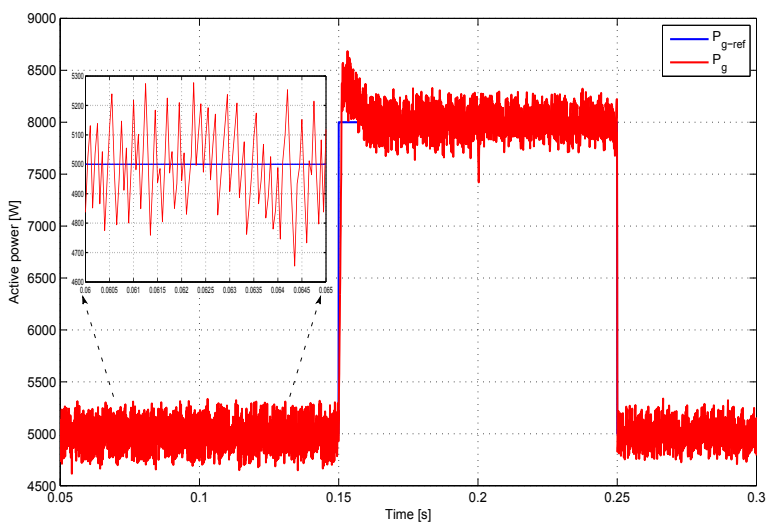

(b) MPPC-VF

Fig. 8: The dynamic response of active power

DPC-SVM [2] for different conditions of references and the same parameters in Table I. To generate the same average switching frequency per semiconductor, the sampling frequency of the MPPC-VF is considered $f_{s}=20 \mathrm{kHz}$ and the sampling frequency of the DPC-SVM is $5 \mathrm{kHz}$. For the SVM at $5 \mathrm{kHz}$, $\overline{f_{s w}}=2.5 \mathrm{kHz}$ and the measured value of $\overline{f_{s w}}$ for MPPC-VF is about $2.5 \mathrm{kHz}$. In order to observe the dynamics ability to track the active and reactive power reference, several power steps has been applied to its references in the grid side. The active power reference presents a steps from $5 \mathrm{~kW}$ to $8 \mathrm{~kW}$ at $\mathrm{t}$ $=0.15 \mathrm{~s}$, then steps from $8 \mathrm{~kW}$ to $5 \mathrm{~kW}$ at $\mathrm{t}=0.25 \mathrm{~s}$ (Fig. 8), while the reactive power reference is changed from $-2 \mathrm{kVar}$ to $2 \mathrm{kVar}$ at $\mathrm{t}=0.2 \mathrm{~s}$ (Fig. 9). The results shown in Figs. 8 and 9 indicate that the active power is tracking the reference with fast dynamics and without affecting the reactive power (the average computation time of the algorithm is $0.17 \mathrm{~ms}$ in a $3.7 \mathrm{GHz}$, i7 CPU, permitting a real time implementation). The proposed method presents better performance compared to the DPC-SVM. The mean absolute percentage error of active and reactive power for DPC-SVM is $4.15 \%$ and $12.15 \%$, whereas, for the proposed method they are $2.07 \%$, and $5.43 \%$, respectively.

The steady state behavior of the inverter phase voltage is performed with the total harmonic distortion (THD) for the proposed method of $15.25 \%$ in comparison with a classical method distortion of $21.92 \%$. The transient responses of the grid current, $i_{a g}$ and its Fast Fourier Transform (FFT) are illustrated in Figs. 10 and 11, where the THD is found to be lower for the proposed method in contrast to the classical controller. The THD of grid current is under the 5\% limit required by the IEEE 519 standards.

At the instant $\mathrm{t}=0.15 \mathrm{~s}$, a resistance load change from $R_{\text {load }}=72 \Omega$ to $R_{\text {load }}=45 \Omega$ is produced. The effect of DC side load on the operation of system is shown in Fig 12. As shown in this figure the change in load doesn't affect DC link voltage and only change the amplitude of the grid current and the grid side active power. One of the important issues of 3L-NPC structure is the balancing voltage of the DC-link 


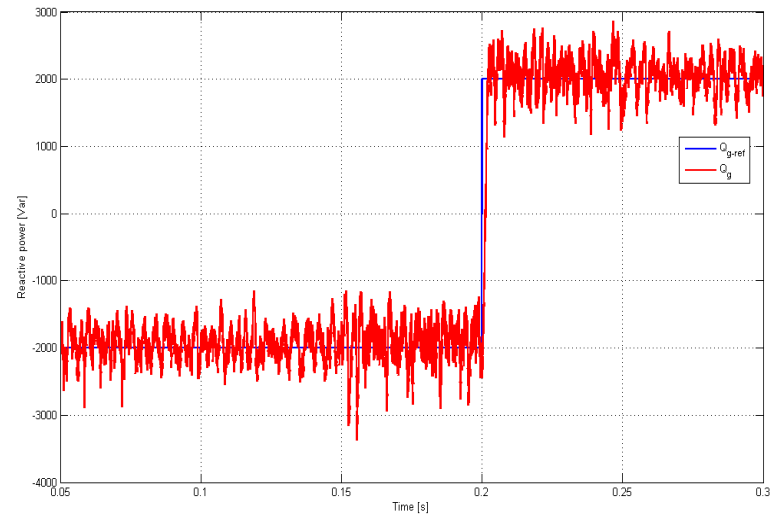

(a) DPC-SVM

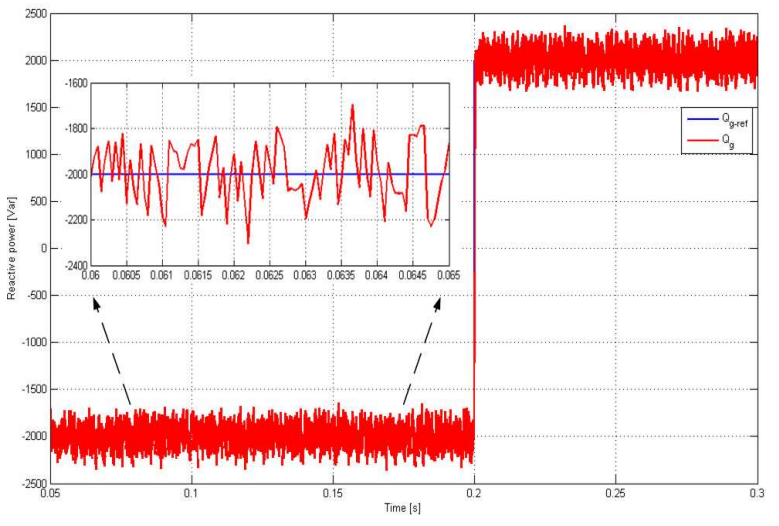

(b) MPPC-VF

Fig. 9: The dynamic response of reactive power

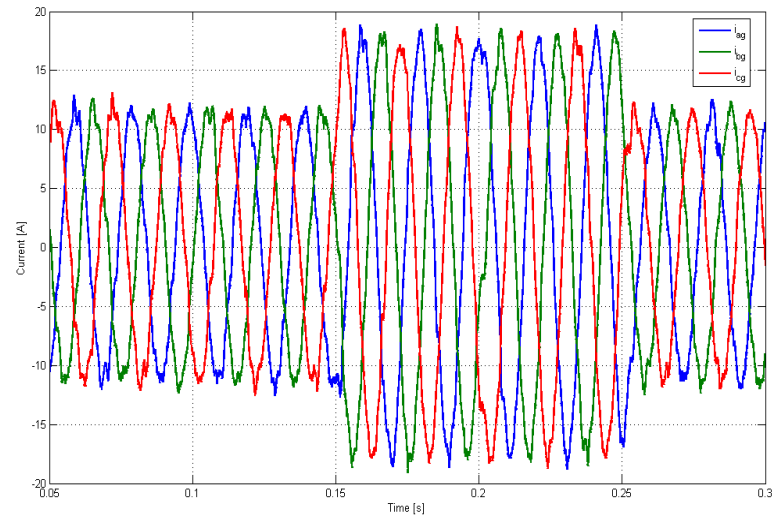

(a) The steady state and transient response of the grid current

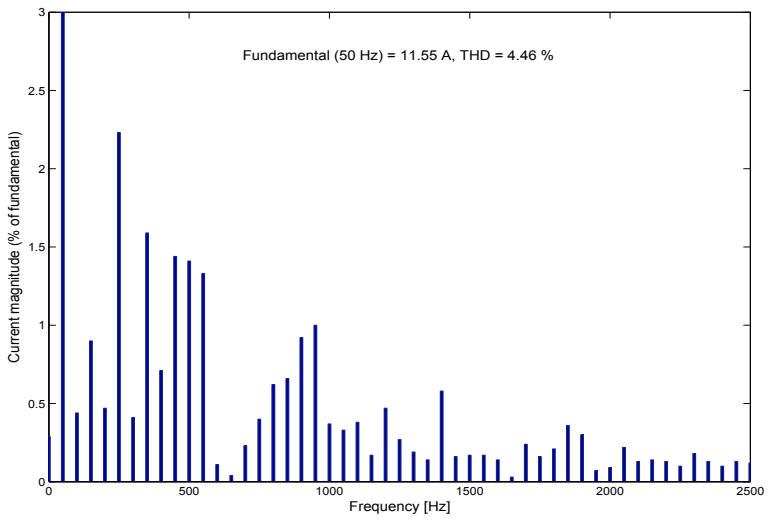

(b) Fast Fourier Transform of the grid current

Fig. 10: The dynamic response and FFT of the grid current for DPC-SVM

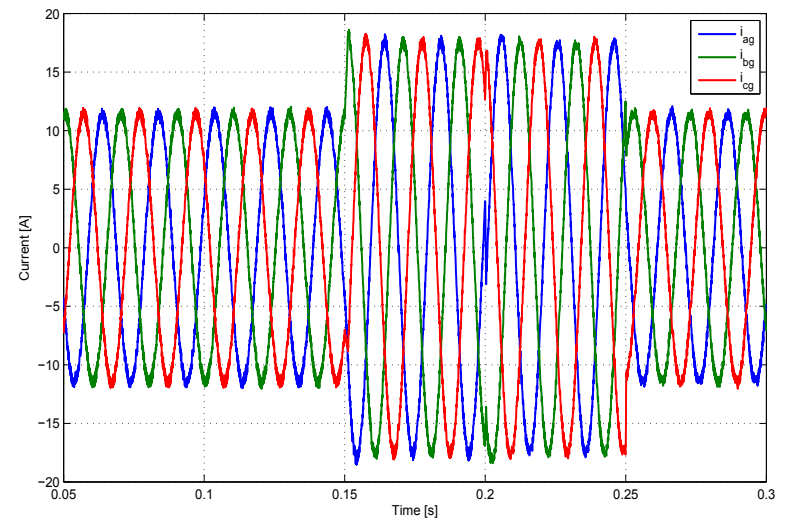

(a) The steady state and transient response of the grid current

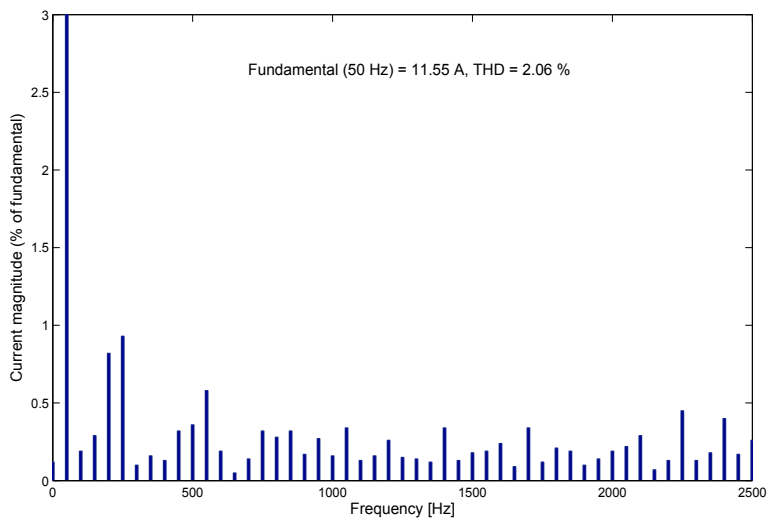

(b) Fast Fourier Transform of the grid current

Fig. 11: The dynamic response and FFT of the grid current for MPPC-VF 


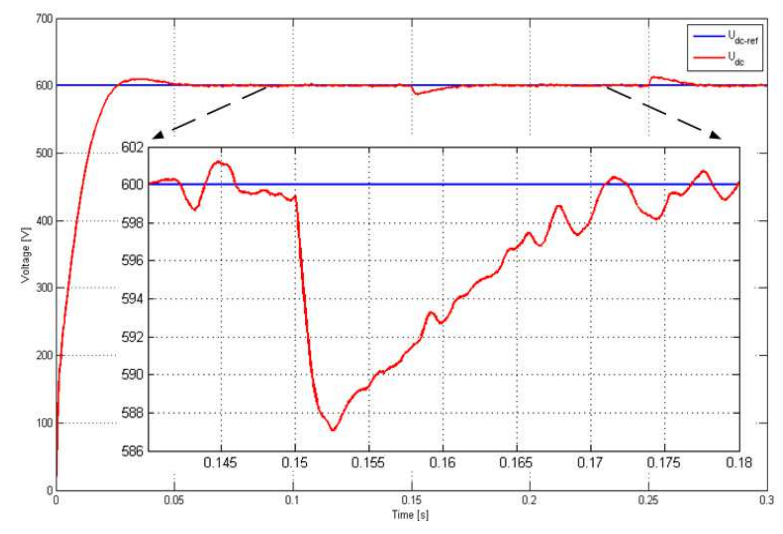

(a) DPC-SVM

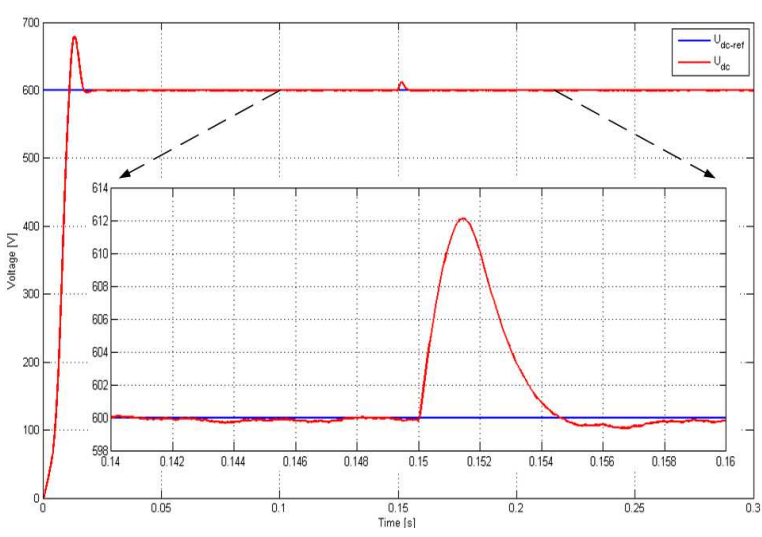

(b) MPPC-VF

Fig. 12: The DC-link voltage response with load change at $\mathrm{t}=0.15[\mathrm{~s}]$

capacitor. It is obvious that the voltage of DC-link capacitor remains balanced with MAPE of DC-link capacitor voltages deviation for MPPC-VF $0.51 \%$ and for DPC-SVM $1.1 \%$ in spite of the transition of the power references (Fig. 7).

\section{Conclusion}

This study proposes the MPPC-VF strategy with two steps prediction for grid connected 3L-NPC inverter. First, the mathematical model of the system is established, and then the cost function, which contains the power error, the capacitor voltage balancing and the reduction of the switching frequency, is established. In this paper, there is a comparison between DPC-SVM and MPPC-VF for 3L-NPC inverter. The simulation results show that the algorithm can successfully track the active and reactive powers, maintain their balanced capacitor voltages and reduce the switching frequency. In addition, by using proposed method we can reduce the switching losses and high number of calculations while maintaining an acceptable quality of current and power. The linear PI controllers for the power, current loops and the modulation block are further eliminated. Therefore, the proposed method is an interesting alternative to control the grid connected 3L-NPC inverter.

\section{References}

[1] Jose Rodriguez and Patricio Cortes.: Predictive Control of Power Converters and Electrical Drives, John Wiley, 2012

[2] Mohamed Abbes and Jamel Belhadji.: New control method of a robust NPC converter for renewable energy source grid connection, Electric Power Systems Research, Vol 88, pp. 52-63, 2012

[3] Mariusz Malinowski, Marian P. Kazmierkowski, Steffan Hansen, Frede Blaabjerg and G. D. Marques.: Virtual-Flux-Based Direct Power Control of Three-Phase PWM Rectifiers, IEEE Transaction On Industrial Electronics, Vol 37 no 4, pp. 1019-1027, 2001

[4] L. A. Serpa and J. W. Kolar.: Virtual-Flux Direct Power Control for Mains Connected Three-Level NPC Inverter Systems, Proceeding of Power Conversion Conference PCC ’07, Nagoya, pp. 130-136, 2007

[5] M. Malinowski, M. Jasinski and M. P. Kazmierkowski.: Simple direct power control of three phase pwm rectifier using space vector modulation (dpc-svm), IEEE Transaction On Industrial Electronics, Vol 51 no 2 , pp. 447-454, 2004

[6] James Scoltock, Tobias Geyer and Udaya K. Madawala.: Model Predictive Direct Power Control for GridConnected Neutral-Point-Clamped Converters, IEEE Transaction On Industrial Electronics, Vol 62 no 9, pp. 5319-5328, 2015

[7] Jose Rodriguez, Marian P. Kazmierkowski, Jose R. Espinoza, Pericle Zanchetta, Haitham Abu-Rub, Hector A. Young and Christian A. Rojas.: State of the Art of Finite Control Set Model Predictive Control in Power Electronics, IEEE Transaction on Industrial Informatics, Vol 9 no 2, pp. 1003-1016, 2013

[8] P. Cortes, J. Rodriguez, P. Antoniewicz and M. Kazmierkowski.: Direct Power Control of an AFE Using Predictive Control, IEEE Transactions on Power Electronics, Vol 23 no 5, pp. 2516-2523, 2008

[9] B. Q. V. Ngo, P. R. Ayerbe and S. Olaru.: Model Predictive Control with Two-step horizon for Three-level Neutral-Point Clamped inverter, Proceeding of 20th International Conference on Process Control, Slovakia, pp. 215-220, 2015 